
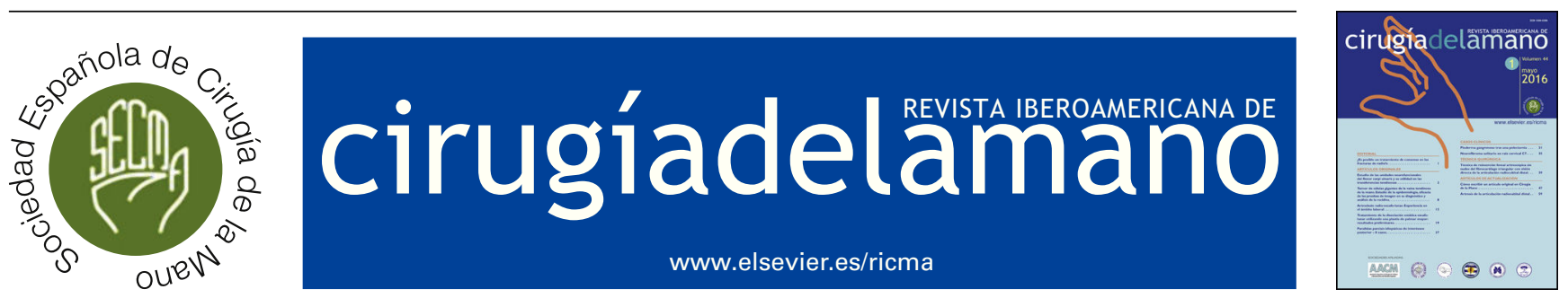

ARTÍCULO ORIGINAL

\title{
Colgajos libres en cirugía de la mano: nuestra experiencia en 49 casos
}

\section{A. Garcia Villanueva*, I. Roger de Ona, A. Studer de Oya y J.I. García López}

\author{
Unidad de Microcirugía, Hospital FREMAP, Majadahonda, Madrid, España
}

Recibido el 26 de abril de 2016; aceptado el 6 de septiembre de 2016

Disponible en Internet el 12 de octubre de 2016

\section{PALABRAS CLAVE \\ Colgajos libres; \\ Reconstrucción microquirúrgica; Mano; \\ Cobertura cutánea}

\begin{abstract}
Resumen
Objetivo: Revisar los colgajos libres utilizados más frecuentemente en la reconstrucción de la mano y evaluar sus resultados, ventajas y complicaciones.

Material y método: Entre el 2011 y el 2014, 49 pacientes fueron intervenidos mediante diferentes transferencias microquirúrgicas, con una edad media de 41 años (25-57). En función de la localización del defecto, se han realizado: a) 29 colgajos libres para los dedos; b) 11 transferencias libres para cobertura de la mano, diferenciando entre zona dorsal de la mano y primera comisura: 5 pacientes; zona volar: 2 pacientes, y cobertura de ambas simultáneamente: 4 pacientes, y c) 9 transferencias óseas vascularizadas para seudoartosis (7 casos) y reconstrucción de articulaciones ( 2 casos) en la mano y los dedos.

Los resultados fueron evaluados en términos de supervivencia del colgajo, complicaciones, reintervenciones y satisfacción del paciente. Además, en los casos de afectación de los pulpejos de los dedos, también se valoró el índice de discriminación de 2 puntos.

Resultados: El porcentaje de supervivencia del colgajo fue del 100\%. En 5 casos fue necesaria una tenoartrólisis secundaria y en otro caso (lateral de brazo para cobertura volar de 4 dedos) se intervino al paciente en 2 ocasiones más para la separación completa de los dedos. Se obtuvieron buenos resultados estéticos y funcionales en todos los pacientes, con alto grado de satisfacción. Los pacientes con afectación del pulpejo obtuvieron una media en el índice de discriminación de 2 puntos de $9,1 \mathrm{~mm}(8-11)$.

Conclusiones: En nuestra opinión, el uso de colgajos libres en cirugía de la mano proporciona un mejor resultado, sin sacrificar - a diferencia de los colgajos locales-, otras zonas sanas de la mano, consiguiéndose una mínima morbilidad de la zona donante y muy buenos resultados estéticos y funcionales.

(c) 2016 SECMA. Publicado por Elsevier España, S.L.U. Este es un artículo Open Access bajo la licencia CC BY-NC-ND (http://creativecommons.org/licenses/by-nc-nd/4.0/).
\end{abstract}

\footnotetext{
* Autor para correspondencia.

Correo electrónico: andrea.g.villanueva@hotmail.com (A. Garcia Villanueva).
} 


\section{KEYWORDS}

Free flaps;

Microsurgical

reconstruction;

Hand;

Soft tissue coverage
Free flaps in hand surgery: Experience in 49 cases

\section{Abstract}

Objective: To review the free flaps most frequently used in hand reconstruction and evaluate their results, advantages and complications.

Material and methods: A total of 49 patients, with a mean age of 41 years old (25-57), underwent different microsurgical transfers for hand reconstruction between 2011 and 2014 . The type of transfer performed depended on the location of the defects: a) 29 free flaps for finger reconstruction, b) 11 free transfers for hand coverage (dorsal coverage and first web space: 5 patients; volar hand defects: 2 patients; coverage of both regions of the hand at the same time: 4 patients, and c) 9 free vascularised bone transfers for non-unions (7 cases) and joint reconstructions ( 2 cases) in hand and fingers.

The results were evaluated in terms of flap survival, complications, secondary procedures, and patient satisfaction. In addition, when fingertip reconstruction was involved, the two-point discrimination test was also assessed.

Results: The survival rate was $100 \%$. A secondary tenolysis was necessary in 5 cases, and another patient underwent two more surgeries to split the fingers (lateral arm used for volar coverage of the fingers). Good aesthetic and functional results and a high level of satisfaction were obtained. The means 2-PD in fingertip reconstruction was $9.1 \mathrm{~mm}$ (8-11).

Conclusions: In our opinion, the use of free flaps for hand surgery reconstruction provides better outcomes, without sacrificing, in contrast to local flaps, other areas of the hand, with good aesthetic and functional results, as well as low donor site morbidity.

(c) 2016 SECMA. Published by Elsevier España, S.L.U. This is an open access article under the CC BY-NC-ND license (http://creativecommons.org/licenses/by-nc-nd/4.0/).

\section{Introducción}

La compleja especialización tanto anatómica como funcional de la mano condiciona unos requerimientos especiales que debemos tener en cuenta en la reconstrucción de sus lesiones. El término «cirugía reconstructiva» incluye un enfoque global que permite el restablecimiento simultáneo de la apariencia y la función de la mano ${ }^{1}$. A pesar de los numerosos colgajos locales descritos, las mejoras en el desarrollo de la microcirugía han proporcionado técnicas adicionales que enriquecen el armamento de la cirugía reconstructiva ${ }^{2,3}$.

Cuando Mathes y Nahai ${ }^{4}$ presentaron su esquema de la escalera reconstructiva, tenían como principal objetivo el cierre cutáneo de un defecto, desde el método más simple al más complejo. Sin embargo, hoy en día no basta con una adecuada cobertura, sino que debemos restaurar la función. Esto supone dar la vuelta a la escalera, convirtiendo los colgajos libres, en ciertas ocasiones, en el primer escalón como mejor opción reconstructiva ${ }^{5}$.

El uso de colgajos libres en cirugía de la mano ha ido en aumento, no solo por una mejor formación de los cirujanos, sino también por las especiales consideraciones que merecen cada una de sus zonas ${ }^{6-8}$. Para maximizar los resultados en estética y función, el cirujano debe tener presente estas propiedades, que orientan la planificación de una reconstrucción óptima:

La piel dorsal de la mano y la muñeca es muy delgada, móvil y flexible, proporcionando una cobertura adecuada para el deslizamiento de los tendones extensores. Su gran elasticidad permite además el movimiento sin restricciones de las articulaciones subyacentes.
Por el contrario, la piel palmar en la mano es gruesa y duradera, sin pelo y relativamente inelástica, diseñada para soportar las fuerzas encontradas durante las actividades diarias. Constituida por diferentes capas bien definidas que le aportan sus características especiales en cuanto a estabilidad, resistencia y sensibilidad simultáneamente.

El pulpejo es una subunidad altamente especializada del dedo. Su anatomía única la convierte en una estructura crítica para la sensibilidad, la manipulación fina, la prensión y el agarre. La reconstrucción del pulpejo del pulgar merece una atención especial, puesto que solo este dedo supone el $40 \%$ de la función global de la mano y es un elemento indispensable para realizar la pinza y la oposición.

Existen numerosas posibilidades locales que permiten solventar un problema de cobertura en la mano, sin embargo, no siempre constituyen la mejor opción terapéutica. Cuando añadimos además afectación ósea, el uso de técnicas tradicionales puede ser insuficiente en casos de pérdida de articulaciones o seudoartrosis recalcitrantes. Restaurar la apariencia y función de la mano, junto con las preferencias del paciente y su demanda laboral, son puntos clave que orientan a la elección de un tratamiento óptimo.

El propósito del presente estudio es presentar los colgajos libres utilizados más frecuentemente en la reconstrucción de la mano y evaluar sus indicaciones, resultados y complicaciones.

\section{Material y método}

Se realizó una revisión retrospectiva de todos aquellos pacientes que fueron intervenidos en el Hospital FREMAP de Majadahonda (Madrid), mediante diferentes técnicas 
Tabla 1 Distribución de colgajos libres según la localización del defecto

\begin{tabular}{lc}
\hline Localización del defecto & N. ${ }^{\circ}$ pacientes \\
\hline Dedos & 38 \\
Solo cobertura & 29 \\
Reconstrucción ósea & 9 \\
Mano & 11 \\
Zona dorsal $+1 .^{\text {a }}$ comisura & 5 \\
Zona volar & 2 \\
Ambas simultáneamente & 4 \\
\hline
\end{tabular}

Tabla 2 Tipos de colgajos libres utilizados en cirugía reconstructiva de la mano

\begin{tabular}{|c|c|c|}
\hline Colgajo libre & Defecto & $\begin{array}{l}\text { N. }{ }^{\circ} \\
\text { pacientes }\end{array}$ \\
\hline Medialis pedis (MP) & Dorsal/volar-dedo & 6 \\
\hline $\begin{array}{l}\text { Hemipulpejo del hallux } \\
\text { (HP) }\end{array}$ & Pulpejo dedo & 14 \\
\hline Lateral de brazo & $\begin{array}{l}\text { Volar-dedo } \\
\text { único/multidigital }\end{array}$ & 5 \\
\hline $\begin{array}{l}\text { Neurocutáneo }-2 .^{\circ} \\
\text { dedo del pie }\end{array}$ & Volar-dedo & 4 \\
\hline $\begin{array}{l}\text { Colgajo tenar } \\
\text { modificado (RASP) }\end{array}$ & Dorsal/volar-dedo & 2 \\
\hline $\begin{array}{l}\text { Anterolateral de muslo } \\
\text { (ALT) }\end{array}$ & $\begin{array}{l}\text { Mano (grandes } \\
\text { defectos) }\end{array}$ & 7 \\
\hline Músculo gracilis & $\begin{array}{l}\text { Mano (grandes } \\
\text { defectos) }\end{array}$ & 1 \\
\hline Inguinal & Mano & 1 \\
\hline Corticoperióstico (CP) & $\begin{array}{l}\text { Seudoartrosis } \\
\text { reclacitrante }\end{array}$ & 6 \\
\hline Peroné vascularizado & $\begin{array}{l}\text { Defecto óseo } \\
\text { diafisario }\end{array}$ & 1 \\
\hline $\begin{array}{l}\text { Articulación } \\
\quad \text { vascularizada del pie }\end{array}$ & $\begin{array}{l}\text { Defecto óseo } \\
\text { articular }\end{array}$ & 2 \\
\hline
\end{tabular}

microquirúrgicas aplicadas a la mano, entre el 2011 y el 2014. Se intervinieron un total de 49 pacientes, 5 mujeres y 44 varones con una edad media de 41 años (25-57), todos ellos con trabajos de media-alta demanda funcional. El mecanismo lesional implicado fue principalmente el atrapamiento en el $82 \%$ de los pacientes, seguido de la inyección de sustancias a alta presión en el $10 \%$ y quemaduras en el $8 \%$. La distribución según la localización del defecto se muestra en la tabla 1.

La elección del tipo de colgajo se realizó fundamentalmente en función de la localización del defecto y tamaño del mismo, adaptando en la medida de lo posible las diferentes propiedades de las áreas de la mano (tabla 2). Los colgajos libres más utilizados en la reconstrucción de los dedos fueron los hemipulpejos del hallux (HP) en 14 pacientes; en las lesiones extensas de la mano, el colgajo anterolateral del muslo (ALT) en 7 pacientes, y en los casos de seudoartrosis recalcitrante, el colgajo corticoperióstico de cóndilo femoral interno (CP) en 6 pacientes.

Los resultados fueron evaluados en términos de supervivencia del colgajo, complicaciones, reintervenciones y satisfacción del paciente. Los criterios de consolidación ósea se basaron en datos clínicos y hallazgos radiológicos. Además, en los casos de afectación de los pulpejos de los dedos, también se valoró el índice de discriminación de 2 puntos.

\section{Resultados}

De los 49 pacientes intervenidos entre el 2011 y el 2014 para la reconstrucción de lesiones en los dedos y la mano, se logró una supervivencia global del colgajo del 100\%. En todos los casos con defectos cutáneos se obtuvo una cobertura estable con alto grado de satisfacción estética.

En la reconstrucción del pulpejo, se consiguió una media de $9 \mathrm{~mm}(8-10)$ en el test de discriminación estática (s2-PD) y de $10,1 \mathrm{~mm}(8-12)$ en el test de discriminación dinámica (d2-PD). Ninguno de los pacientes presentó intolerancia al frío posteriormente.

La tasa de consolidación ósea fue del 100\%. Datos clínicos de consolidación (ausencia de dolor y de aflojamiento del material de osteosíntesis en radiología simple) se observaron entre los 3-5 meses. Sin embargo, la evidencia radiológica (puente óseo consistente a través del trazo de fractura) no se observó hasta los 4-8 meses. Tras un tratamiento rehabilitador comenzando a partir de la cuarta semana tras la cirugía, todos los pacientes recuperaron un rango funcional de movimiento.

El paciente al que se le realizó una reconstrucción ósea del primer radio mediante transferencia de peroné vascularizado requirió una revisión quirúrgica en las primeras $24 \mathrm{~h}$, por trombosis venosa, que se solventó con éxito tras rehacer la anastomosis.

Los 2 casos de reconstrucción con articulaciones vascularizadas, así como 2 casos más de colgajos corticoperiósticos (seudoartrosis en falanges de los dedos), se reintervinieron realizándose tenoartrólisis secundarias. En uno de los pacientes, se utilizó un único colgajo lateral del brazo para un defecto de cobertura volar múltiple, reinterviniéndose en 2 ocasiones más para individualizar cada uno de los dedos.

Se realizaron 3 revisiones estéticas ( 2 hemipulpejos, uno lateral de brazo) para reducir el volumen del colgajo inicial.

En cuanto a las complicaciones de la zona donante, se han encontrado 3 pérdidas parciales del injerto de piel en los casos de pedialis pedis, que requirieron curas periódicas hasta la cicatrización completa. Además, 2 de los pacientes a los que se les realizó un colgajo corticoperióstico y 3 de los intervenidos utilizando el colgajo anterolateral del muslo presentaron parestesias transitorias en el territorio del nervio safeno y nervio del femoral superficial respectivamente, que desaparecieron a los 2-3 meses.

\section{Discusión}

En los últimos años, la utilización de colgajos libres en cirugía reconstructiva se ha convertido en un elemento fundamental del arsenal terapéutico. El desarrollo de las técnicas microquirúrgicas y un mayor conocimiento de la anatomía han permitido mejorar nuestra habilidad para reconstruir lesiones complejas de la mano y los dedos.

La utilización de colgajos libres en cirugía de la mano ofrece una buena y estable cobertura, aportando un tejido vascularizado de zonas del cuerpo ajenas al área de la lesión. 

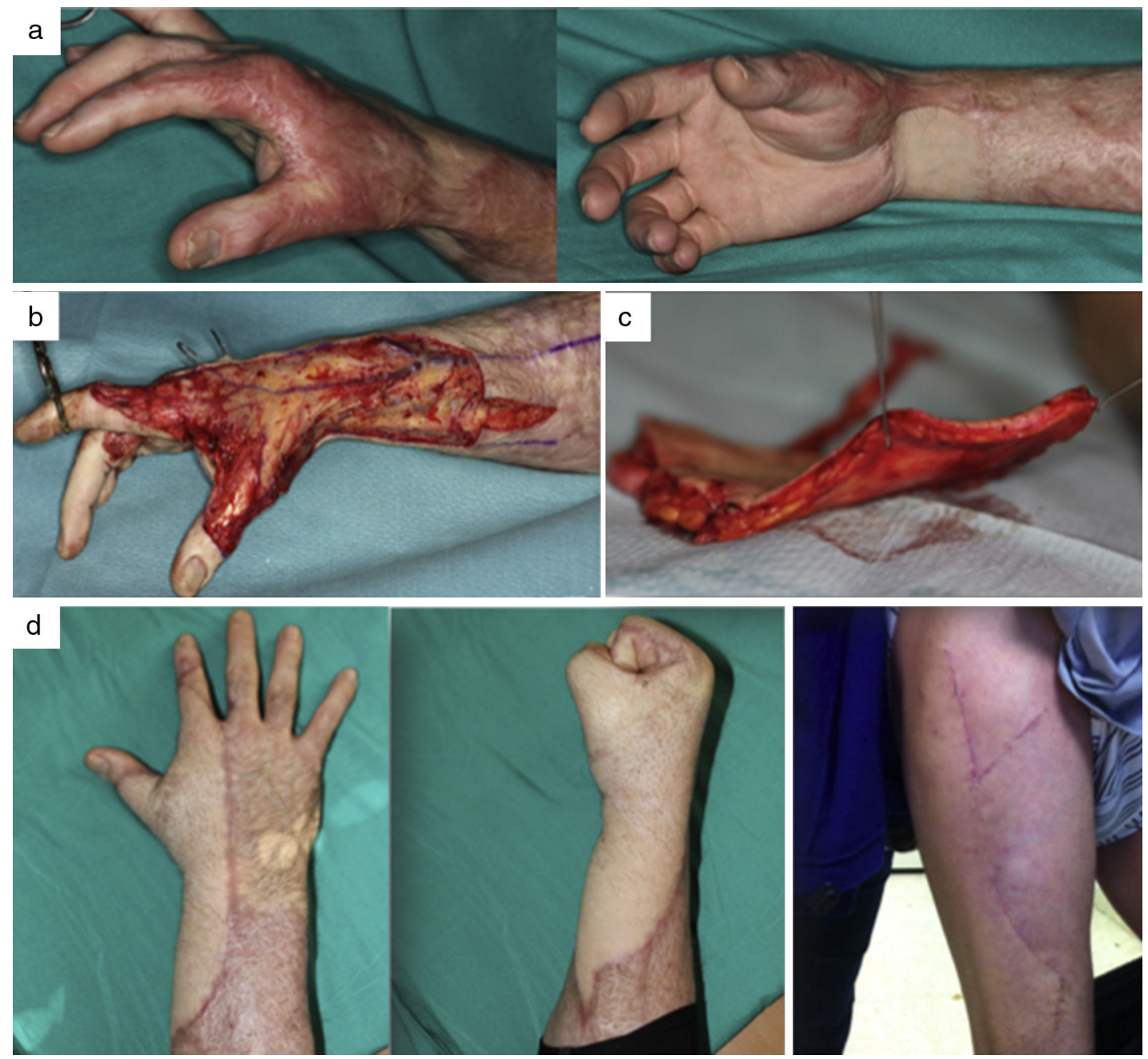

Figura 1 a) Varón de 49 años con secuelas de quemaduras en la mano derecha: retracción cutánea en muñeca y primera comisura. b) Resección del tejido cicatricial. c) Cobertura mediante colgajo anterolateral del muslo-disección. La imagen muestra como la disección por encima de la fascia de Scarpa permite sacar un colgajo fasciograso fino. d) Resultado final sin necesidad de adelgazamiento posterior del colgajo y cierre directo de la zona donante.

El desafío hoy en día es proporcionar de manera simultánea el mejor resultado no solo funcional, sino también estético, con la mínima morbilidad de la zona donante. Se debe ofrecer al paciente la mejor opción reconstructiva considerando de forma global sus necesidades y requerimientos de la lesión, a pesar de la complejidad del procedimiento ${ }^{7,9}$.

La elección del colgajo libre a utilizar es muy amplia y la decisión debe tomarse considerando varios factores, entre los que se encuentran fundamentalmente el tipo de paciente, las características y la localización del defecto, y los condicionantes estéticos.

Los colgajos musculares se han utilizado tradicionalmente para la cobertura tras desbridamientos amplios con superficies irregulares. Son colgajos con buena perfusión que se adaptan muy bien al contorno del defecto. En cirugía de la mano, los colgajos musculares más utilizados son el gracilis o las transferencias parciales de músculo dorsal ancho.

Parrett et al. ${ }^{8}$ definían en su serie a estos colgajos como los que mejor puntuaban en cuanto a resultados estéticos, coloración y contorno para defectos en el dorso de la mano, con resultados similares a los colgajos fasciales. Esto es probablemente debido a la atrofia muscular que sufren con el tiempo. Sin embargo, el uso de estos colgajos requiere siempre de injerto de piel parcial posterior, lo que implica lesionar otra zona donante. Además, otros autores no coinciden en que la atrofia muscular sea tan marcada como para evitar el exceso de volumen resultante, sobre todo en una mano $^{2,5}$. En nuestra serie, solo se intervino un paciente con un colgajo muscular de gracilis, que fue utilizado para restablecer la primera comisura tras una transferencia del primer dedo del pie al pulgar de la mano.

Los colgajos fasciocutáneos tienen 2 ventajas fundamentalmente: en primer lugar, son más fáciles de elevar en cirugía secundaria, algo muy frecuente en lesiones complejas de la mano que a menudo requieren procedimientos asociados como tenoartrólisis. En segundo lugar, el tejido del colgajo puede ser dividido y movilizado con menor preocupación por el aporte vascular, puesto que la dependencia del pedículo desparece con los meses, algo que no ocurre en los colgajos musculares. Como principal inconveniente 

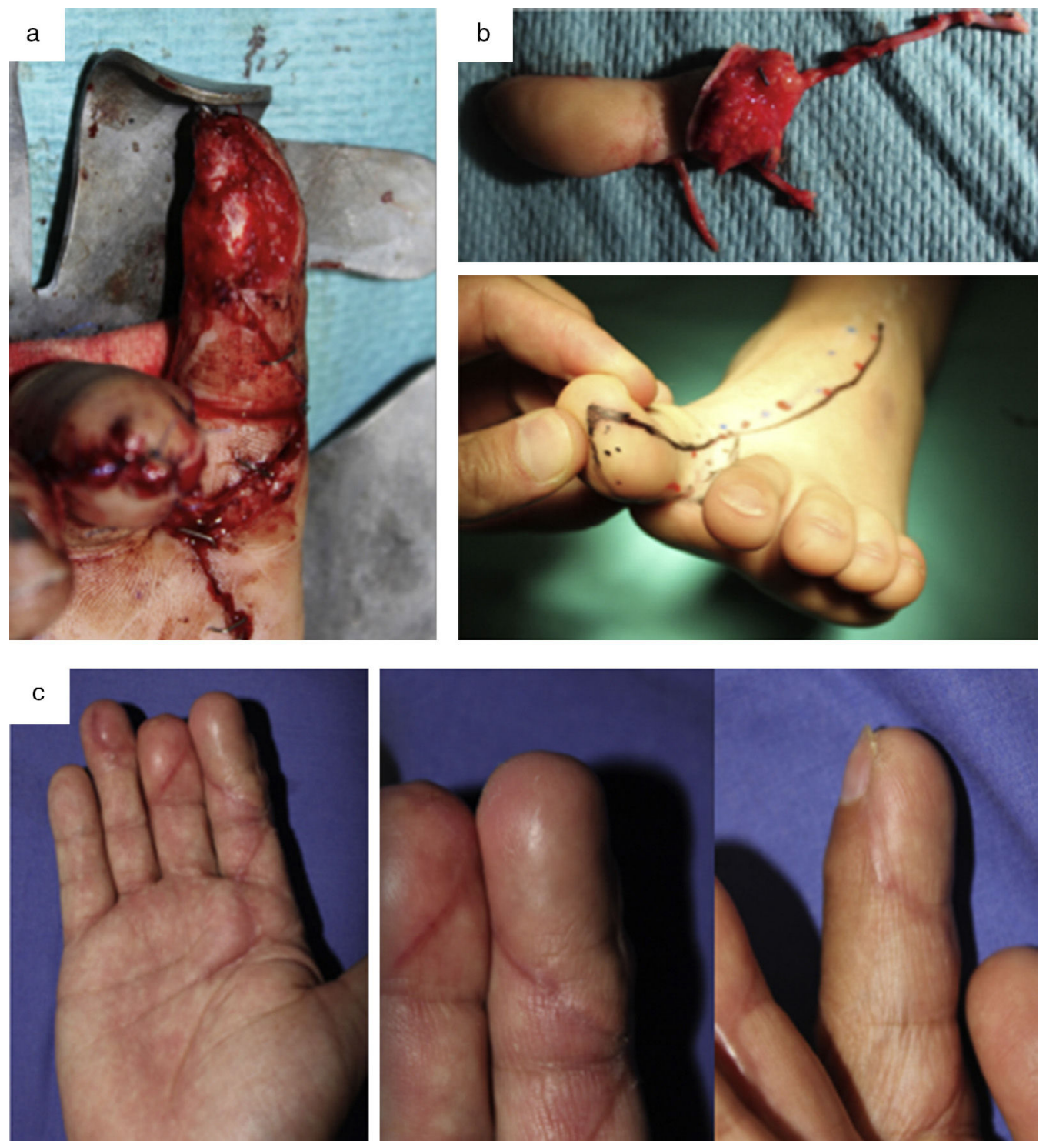

Figura 2 a) Varón de 53 años con pérdida del pulpejo del $2 .^{\circ}$ dedo de la mano derecha (dominante). b) Diseño y transferencia de hemipulpejo del pie. c) Aspecto final de la mano, con una apariencia y función muy similares al pulpejo nativo.

destacan el exceso de volumen y las consiguientes cirugías de revisión para adelgazar el colgajo, especialmente con el colgajo anterolateral del muslo. En nuestra experiencia, esto es algo que puede evitarse si se hace la disección por encima de la fascia de Scarpa, lo que permite obtener un colgajo nada voluminoso y flexible (fig. 1). La zona donante en cirugía de la mano suele permitir el cierre directo, sin necesidad de injertos.

El colgajo libre inguinal es una buena alternativa cuando se requiere una cobertura muy fina y al mismo tiempo, una zona donante oculta y con mínima morbilidad ${ }^{10}$. No obstante, este colgajo ha perdido popularidad debido a su corto pedículo y variable anatomía arterial. El caso de nuestra paciente, mujer joven con un defecto sobre el borde cubital de toda la mano, se solventó con este colgajo teniendo en cuenta no solo las características de la lesión, sino también las preferencias estéticas de la paciente.
Otro de los colgajos frecuentemente utilizados en cirugía de la mano es el colgajo lateral del brazo, basado en la arteria colateral radial posterior, rama de la braquial profunda. Puede reinervarse utilizando el nervio cutáneo lateral del brazo. La posibilidad de hacer una disección sobre la misma extremidad (sin cambio de posición del paciente durante el procedimiento) y el no sacrificio de un vaso principal son sus principales ventajas ${ }^{2,9}$. Por otro lado, la piel suele ser gruesa y puede necesitar procedimientos posteriores para reducir su volumen.

La anatomía única y especializada del pulpejo de los dedos es un componente indispensable en el desempeño de funciones críticas como la sensibilidad, la manipulación fina, y el agarre ${ }^{11}$. Como tal, es importante estar familiarizado con las opciones de tratamiento disponibles para este tipo de lesiones, con el fin de proporcionar el mejor resultado funcional y estético para los pacientes. 

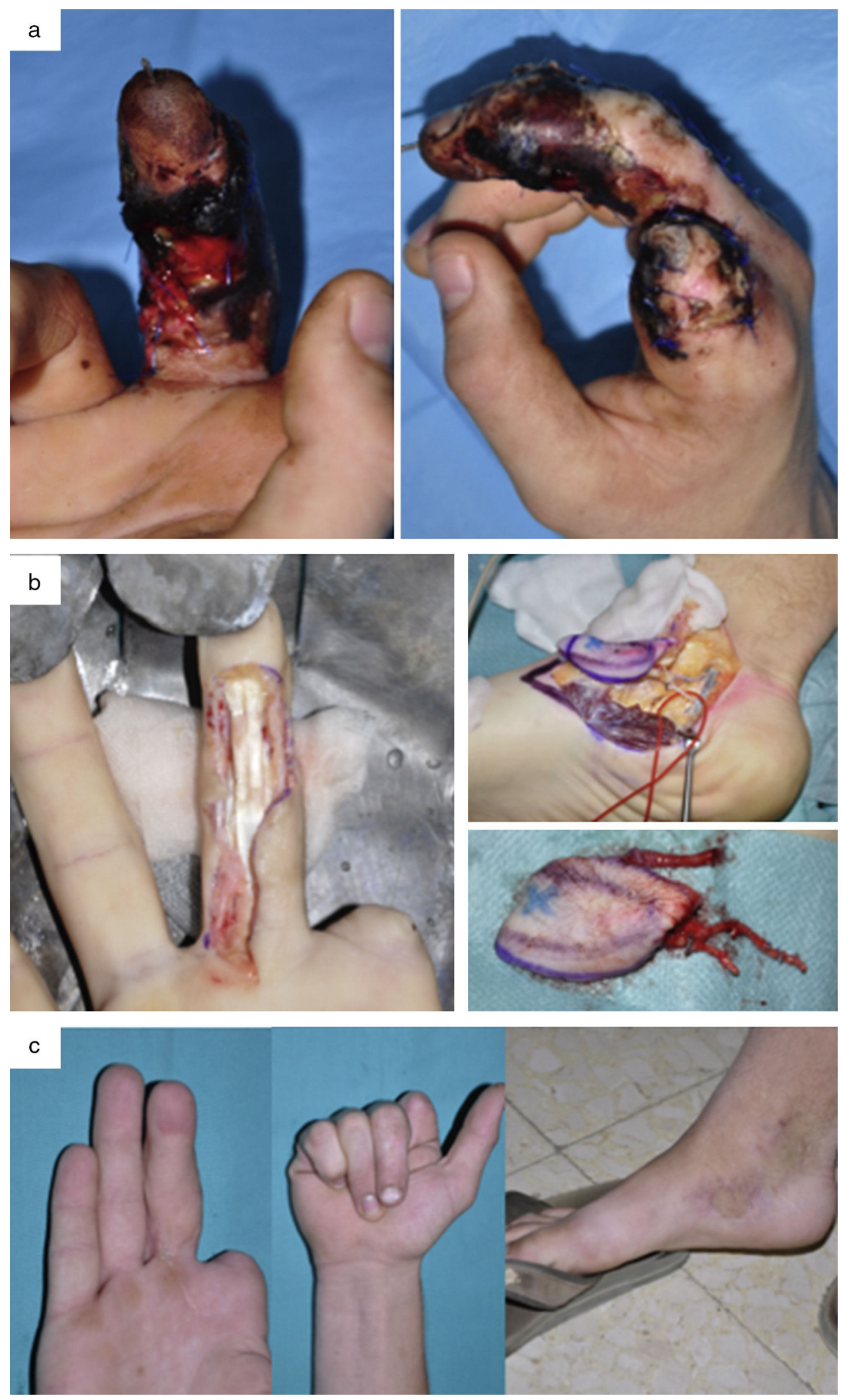

Figura 3 a) Varón de 19 años con amputación del $2 .^{\circ}$ dedo y lesiones en el $3 .^{\text {er }}$ dedo de la mano derecha (dominante) tras el atrapamiento con una radial. b) Desbridamiento y transferencia de colgajo libre medialis pedis para reconstruir el $3 .{ }^{\text {er }}$ dedo. c) Resultado final a los 3 meses en la zona donante y en la zona receptora. 

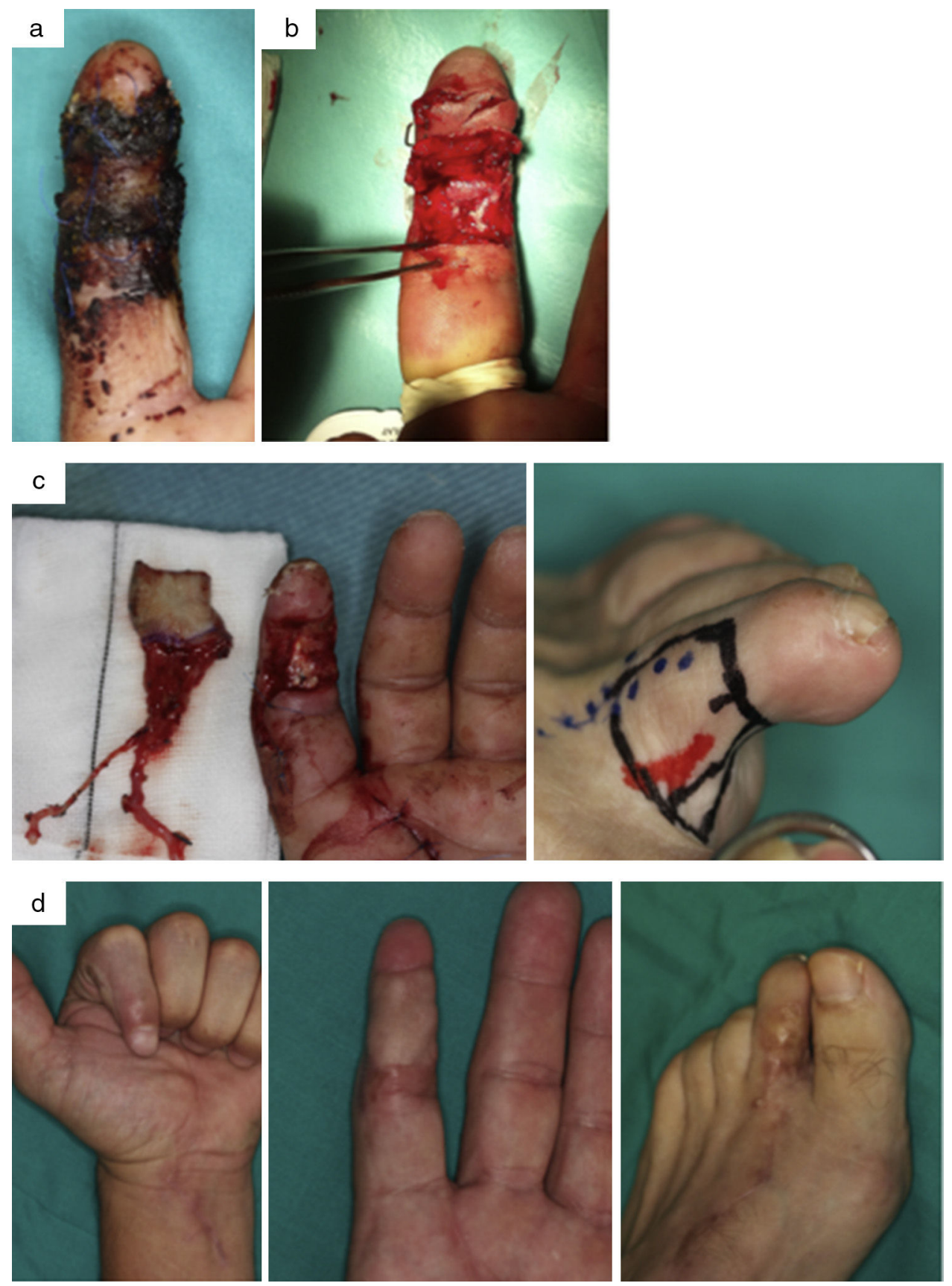

Figura 4 Varón de 41 años con degloving del $2 .^{\circ}$ dedo de la mano izquierda y avulsión de ambos nervios colaterales. a) Necrosis cutánea posterior tras revascularización (lesión nerviosa no reparable inicialmente mediante sutura nerviosa directa). b) Desbridamiento de tejido necrótico. c) Diseño y transferencia de colgajo neurocutáneo del $2 .^{\circ}$ dedo del pie. d) Resultado a los 6 meses en la zona donante y en la zona receptora.

Las transferencias vascularizadas de los hemipulpejos del pie son las que permiten una reconstrucción más similar a la estructura pulpar del dedo nativo (fig. 2). Es un tejido resistente al desgaste y proporciona una superficie estable antideslizante con recuperación simultánea de la sensibilidad y mínima morbilidad en la zona donante ${ }^{12}$.

Cuando los defectos volares son más grandes, incluyendo las falanges medias y proximales de los dedos, el hemipulpejo del pie puede resultar demasiado pequeño. En estas condiciones, la elección de un colgajo libre tenar ofrece una cobertura más extensa y un acceso cómodo durante la cirugía de urgencia (debido a que la zona donante se encuentra dentro del mismo campo operatorio). Sin embargo, su inervación es inconstante. Por ello se describió un nuevo colgajo basado en la rama palmar superficial de la arteria radial (RASP) ${ }^{13}$, que incluía de forma constante una rama cutánea palmar del nervio mediano. Puede usarse también para revascularizar simultáneamente los dedos y permite el cierre directo de la zona donante sin limitación funcional 

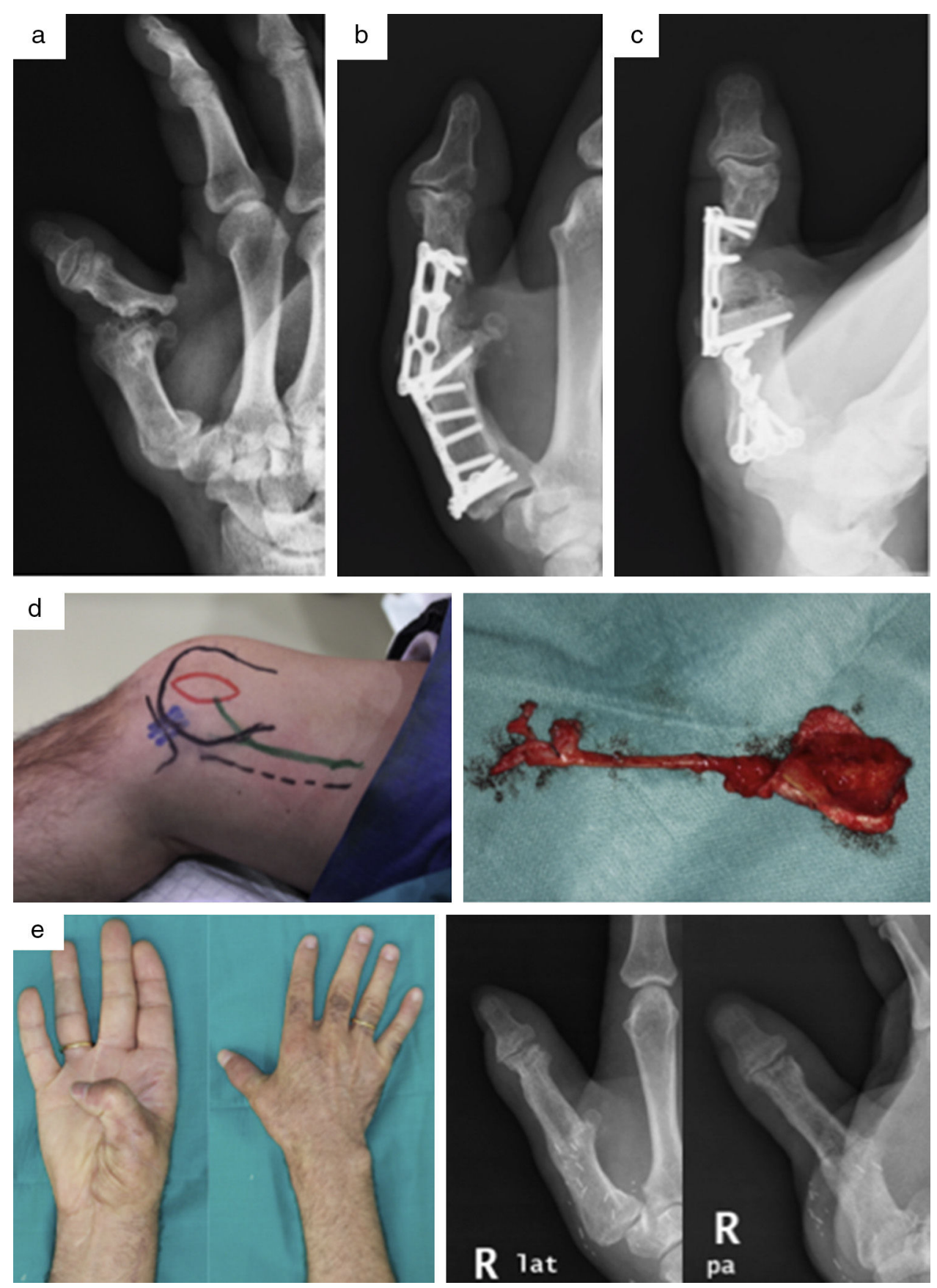

Figura 5 a) Varón de 37 años con seudoartrosis en F1 del pulgar y fracaso de la artrodesis metacarpofalángica de la mano derecha. b) Imagen radiológica del postoperatorio inmediato tras el injerto y la nueva fijación con placa. c) Reabsorción del injerto óseo a los 2 meses. d) Diseño y transferencia de colgajo corticoperióstico. e) Resultado clínico y radiológico con consolidación completa a los 5 meses.

para la abducción del pulgar, siempre que sus dimensiones no sobrepasen los $23,92 \times 77,91 \mathrm{~mm}$.

Inicialmente descrito por Masquelet y Romana como colgajo pediculado ${ }^{14}$, el colgajo medialis pedis ha sido después popularizado de forma libre en la reconstrucción de la mano ${ }^{15}$. La piel de este colgajo es delgada y flexible (fig. 3), y puede utilizarse de forma simultánea para revascularizar los dedos. Sin embargo, también presenta ciertas desventajas. No puede emplearse como colgajo inervado y la zona donante requiere de injertos de piel en la mayoría de las ocasiones. En nuestra serie, las complicaciones derivadas de la zona donante, aunque han sido leves (pérdida parcial del injerto que ha requerido curas periódicas), han estado relacionadas en su mayor parte con este colgajo.

En ocasiones, las lesiones complejas de los dedos asocian al mismo tiempo defectos de cobertura y lesiones nerviosas. Para evitar una reconstrucción en 2 tiempos y los pobres resultados obtenidos con injertos nerviosos o conductos sobre lechos cicatriciales, Del Piñal et al. describen el colgajo neurocutáneo del lado medial del $2 .^{\circ}$ dedo del 
pie $^{16}$. Este colgajo cumple varios requisitos para un injerto nervioso ideal, presenta anatomía constante, pérdida funcional mínima en la zona donante y cuenta con un aporte vascular fiable paralelo al nervio de largo recorrido (fig. 4). De esta manera se consiguen buenos resultados funcionales con una mínima morbilidad en la zona donante.

Por otro lado, la reconstrucción ósea en cirugía de la mano tiene 2 objetivos principales, lograr la consolidación del hueso a la vez que se recupera una función óptima. Cuando las lesiones afectan a las articulaciones interfalángica proximal o metacarpofalángica, el reto es además restablecer una articulación estable, no dolorosa y que permita un arco de movimiento útil. Las transferencias de articulaciones vascularizadas del pie han permitido conseguir resultados satisfactorios, con un rango de movilidad media para la interfalángica proximal de $24^{\circ}$ y de $34^{\circ}$ para la metacarpofalángica ${ }^{17}$. Sin embargo, el ideal de conseguir una articulación con un rango de movimiento normal continúa siendo un reto para el cirujano de la mano.

Se estima que un promedio de 3-4\% de todas las fracturas se complican con seudoartrosis. Para la curación adecuada, una fractura necesita estabilidad y la vascularización adecuada. En aquellos casos con defectos de hasta $4 \mathrm{~cm}$ con seudoartrosis persistentes, se ha utilizado con gran éxito el colgajo corticoperióstico de cóndilo femoral interno (fig. 5). De esta manera se consigue un soporte estructural vascularizado con estímulo osteogénico altamente eficaz en el tratamiento de seudoartrosis persistentes, con tasas de consolidación cercanas al $100 \%{ }^{18}$. A pesar del inicio temprano de la rehabilitación (cuarta semana), 2 de nuestros pacientes requirieron tenoartrólisis secundarias.

\section{Conclusión}

La utilización de colgajos libres en cirugía de la mano proporciona una buena y estable cobertura, además de ofrecer en un solo tiempo la reconstrucción completa en lesiones complejas.

En nuestra opinión, el uso de colgajos libres en cirugía de la mano proporciona un mejor resultado, sin sacrificar, a diferencia de los colgajos locales, otras zonas sanas de la mano, consiguiéndose una mínima morbilidad de la zona donante y muy buenos resultados estéticos y funcionales.

\section{Responsabilidades éticas}

Protección de personas y animales. Los autores declaran que para esta investigación no se han realizado experimentos en seres humanos ni en animales.

Confidencialidad de los datos. Los autores declaran que han seguido los protocolos de su centro de trabajo sobre la publicación de datos de pacientes.

Derecho a la privacidad y consentimiento informado. Los autores han obtenido el consentimiento informado de los pacientes y/o sujetos referidos en el artículo. Este documento obra en poder del autor de correspondencia.

\section{Conflicto de intereses}

Los autores declaran no tener ningún conflicto de intereses.

\section{Bibliografía}

1. Yannascoli SM, Thibaudeau S, Levin LS. Management of soft tissue defects of the hand. J Hand Surg Am. 2015;40:1237-44.

2. Friedrich JB, Katolik LI, Vedder NB. Soft tissue reconstruction of the hand. J Hand Surg Am. 2009;34:1148-55.

3. Karanas YL, Buntic RF. Microsurgical reconstruction of the burned hand. Hand Clin. 2009;25:551-6.

4. Mathes S, Nahai F. Reconstructive surgery. Principles, anatomy and technique. Churchill Livingstone: New York; 1997.

5. Horta R, Silva P, Costa-Ferreira A, Amarante JM, Silva A. Microsurgical soft-tissue hand reconstruction: an algorithm for selection of the best procedure. J Hand Microsurg. 2011;3:73-7.

6. Rehim SA, Kowalski E, Chung KC. Enhancing aesthetic outcomes of soft-tissue coverage of the hand. Plast Reconstr Surg. 2015;135:413e-28e.

7. Upton J, Havlik RJ, Khouri RK. Refinements in hand coverage with microvascular free flaps. Clin Plast Surg. 1992;19:841-57.

8. Parrett BM, Bou-Merhi JS, Buntic RF, Safa B, Buncke GM, Brooks D. Refining outcomes in dorsal hand coverage: Consideration of aesthetics and donor-site morbidity. Plast Reconstr Surg. 2010;126:1630-8.

9. Antohi N, Stingu C, Stan V. The use of free flap transfer in upper extremity reconstruction. Tim Med J. 2005;1:27-35.

10. Hsu WM, Chao WN, Yang C, Fang CL, Huang KF, Lin YS, et al. Evolution of the free groin flap: the superficial circumflex iliac artery perforator flap. Plast Reconstr Surg. 2007;119:1491-8.

11. Panattoni JB, de Ona IR, Ahmed MM. Reconstruction of fingertip injuries: Surgical tips and avoiding complications. J Hand Surg Am. 2015;40:1016-24.

12. Chan BK, Tham SK, Leung M. Free toe pulp transfer for digital reconstruction after high-pressure injection injury. J Hand Surg. 1999;24:534-8.

13. Yang JW, Kim JS, Lee DC, Ki SH, Roh SY, Abdullah S, et al. The radial artery superficial palmar branch flap: a modified free thenar flap with constant innervation. J Reconstr Microsurg. 2010;26:529-38.

14. Masquelet AC, Romana MC. The medialis pedis flap: A new fasciocutaneous flap. Plast Reconstr Surg. 1990;85:765-72.

15. Ishikura N, Heshiki T, Tsukada S. The use of a free medialis pedis flap for resurfacing skin defects of the hand and digits: Results in five cases. Plast Reconstr Surg. 1995;95:100-7.

16. Del Piñal F, García-Bernal FJ, Regalado J, Studer A, Cagigal $\mathrm{L}$, Ayala H. The tibial second toe vascularized neurocutaneous free flap for major digital nerve defects. J Hand Surg Am. 2007;32:209-17.

17. Chen SH, Wei FC, Chen HC, Hentz VR, Chuang DC, Yeh MC. Vascularized toe joint transfer to the hand. Plast Reconstr Surg. 1996;98:1275-84.

18. Rodriguez-Vegas JM, Delgado-Serrano PJ. Corticoperiosteal flap in the treatment of nonunions and small bone gaps: Technical details and expanding possibilities. J Plast Reconstr Aesthet Surg. 2011;51:5-527. 